\title{
EL INICIO DEL FIN. EL MOVIMIENTO TRIGARANTE EN LA PROVINCIA DE GUANAJUATO, 1821
}

\section{THE BEGINNING OF THE END. THE TRIGARANTE MOVEMENT IN THE PROVINCE OF GUANAJUATO, 1821}

\author{
Joaquín E. Espinosa Aguirre \\ Universidad Michoacana de San Nicolás de Hidalgo
}

SUMARIO: I. INTRODUCCIÓN.- II. LA MANZANA DE LA DISCORDIA. EL BAJÍO DURANTE LA GUERRA INSURGENTE.- III. DESATAR EL NUDO SIN ROMPERLO. EL PACÍFICO TRIUNFO DE LA TRIGARANCIA.- IV. A MODO DE CONCLUSIÓN.

Resumen: El movimiento de independencia que se originó a partir de la proclamación del Plan de Iguala, el 24 de febrero de 1821, pasó serios apuros durante los días posteriores a su publicación, pues las autoridades virreinales realizaron un despliegue militar sobre la comandancia del Sur, donde se encontraban Agustín de Iturbide y Vicente Guerrero, lo que acotó su movilidad y campo de acción. En ese marco, cobró relevancia el triunfo sobre diversos poblados del Bajío guanajuatense que a mediados del mes de marzo consiguieron los comandantes militares de la región, ya que ello impulsó al movimiento y permitió que la causa trigarante se fortaleciera en la región central del virreinato, logrando abrir el camino hacia la obtención final de la independencia.

\begin{abstract}
The independence movement that originated from the proclamation of the Plan of Iguala, on February 24, 1821, suffered serious difficulties during the days after its publication, as the viceregal authorities carried out a military deployment over the command of the South, where Agustin de Iturbide and Vicente Guerrero were present, which limited their mobility and field of action. In this framework, the triumph over various towns in the Guanajuato Bajio that the region's military commanders achieved in mid-March gained relevance, since this boosted the movement and allowed the Trigarante cause to be strengthened in the central region of the viceroyalty. managing to open the way to finally obtaining independence.
\end{abstract}

Palabras clave: Independencia mexicana, Consumación, Guanajuato, Anastasio Bustamante, Bicentenario.

Key Words: Mexican Independence, Consummation, Guanajuato, Anastasio Bustamante, Bicentennial.

\section{INTRODUCCIÓN}

Al momento de conocerse en el reino de Nueva España que la Monarquía toda regresaba al régimen constitucional abolido en 1814, las diversas provincias a su interior se encontraban en graves problemas económicos, a los que se sumaban los conflictos sociales generados por el deterioro de una guerra destructiva y desgastante que se había prolongado durante una década. Aunado a esto, por si 
fuera poco, en muchos espacios del virreinato existía un número excesivo de contingentes armados, los cuales habian comenzado a imponerse como una fuerza fáctica que de un momento a otro podría poner en jaque a las autoridades españolas.

En ese entorno sobresale la provincia de Guanajuato, origen de la revolución del año de 1810 y cuya importancia a lo largo de la década de guerra no cejó, tanto para la economía virreinal como para la contrainsurgencia que pusieron en práctica los virreyes, desde Francisco Xavier Venegas (1810-1813) y Félix María Calleja (1813-1816) hasta Juan Ruiz de Apodaca (1816-1821) y Francisco Novella (1821). Lo mismo sucedió para el bando insurgente, que comisionó a comandantes militares, representantes de sus instituciones politicas, para que expandieran el dominio de la causa rebelde al tiempo de obtener recursos para seguir la guerra.

Sobre esta región en el periodo de la guerra son destacados los trabajos de notables investigadores de finales del siglo pasado, como Eric Wolf, Brian Hamnett y David Brading, ${ }^{1}$ quienes realizaron los primeros acercamientos al estudio de su entorno geográfico, la economía agrícola y la minera, así como su papel en la guerra de independencia y la construcción del Estado mexicano. Pero sobre todo resaltan las obras de las últimas dos décadas que ha dado a conocer José Antonio Serrano, quien ha abordado el desenvolvimiento de la insurgencia en sus pueblos, las fricciones sociales que aparecieron a consecuencia de la lucha armada dentro de la élite y la reacción en los círculos jerárquicos de las ciudades más importantes de la región. Serrano ha demostrado cómo el conflicto armado impactó sobre el aparato político, lo que causó que las poblaciones mudaran sus condiciones económicas y sociales. $^{2}$

Importantes aportaciones han significado también los estudios de Graciela Bernal, quien ha estudiado los procesos politicos y sociales de la segunda mitad del siglo XVIII y los inicios del XIX, centrándose en las instituciones gubernamentales, el ayuntamiento guanajuatense sobre todo, así como los diversos gobiernos municipales del Bajío, denominados subdelegaciones. ${ }^{3} \mathrm{Y}$

\footnotetext{
1 Sobre todo me parecen útiles, de Eric Wolf, "El Bajio en el siglo XVIII. Un análisis de integración cultural", David Barkin (comp.), Los beneficiarios del desarrollo regional, México, SEP Setentas, 1972, pp. 63-95; de Brian R. Hamnett, Raices de la insurgencia en México. Historia regional 1750-1824, traducción de Agustín Bárcena, México, Fondo de Cultura Económica, 1990, así como "Royalist Counter-insurgency and the Continuity of Rebellion: Guanajuato and Michoacán, 1813-1820", Hispanic American Historical Review, LXII: 1, febrero 1982, pp. 19-48; y de David A. Brading, Haciendas y ranchos del Bajío. León 1700-1860, traducción de Elia Villanueva Moreno, México, Grijalbo, 1988.

2 José Antonio Serrano Ortega, Jerarquía territorial y transición politica. Guanajuato 1790-1836, Zamora, El Colegio de Michoacán / Instituto de Investigaciones Dr. José María Luis Mora, 2001; "La jerarquía subvertida: ciudades y villas en la intendencia de Guanajuato, 1787-1820", Marta Terán y José Antonio Serrano Ortega (edit.), Las guerras de independencia en la América española, México, El Colegio de Michoacán / Universidad Michoacana de San Nicolás de Hidalgo / Conaculta-INAH, 2002, pp. 403-422; "Dolores después del grito. Estrategias militares insurgentes y realistas en el norte de Guanajuato, 1810-1821", Tzintzun. Revista de Estudios Históricos, 61, enero-junio 2015, pp. 11-48.

3 Sobre todo Graciela Bernal Ruiz, "Las ciudades de San Luis Potosí y Guanajuato en defensa de su preeminencia, 1786-1821", en Rubrica Contemporánea, vol. VIII, n. 15, 2019, pp. 5-24; "E1 papel de los subdelegados en la contrainsurgencia. Guanajuato, 1810-1812", Rafael DiegoFernández Sotelo, María del Pilar Gutiérrez Lorenzo y Luis Alberto Arrioja Díaz Viruell (coord.), De reinos y subdelegaciones: nuevos escenarios para un nuevo orden en la América borbónica, Zamora, El Colegio de Michoacán / Universidad de Guadalajara / El Colegio Mexiquense, 2014, pp. 347-
} 
finalmente, debo consignar los trabajos previos que he realizado en torno a los aspectos militares, económicos y políticos de la intendencia de Guanajuato, donde he analizado el papel que jugó en la provincia la militarización castrense sufrida a partir de 1813, el sistema de juntas de arbitrios fomentado por las autoridades durante la restauración, así como el tránsito suscitado por las fuerzas armadas guanajuatenses entre el gobierno absolutista y el de la nación independiente, hasta la república federal (1824). ${ }^{4}$

Este trabajo pretende estudiar la importancia trascendental que tuvo la intendencia de Guanajuato como parte de la región conocida como el Bajío, la cual estuvo en pugna entre los bandos combatientes y cambió de manos a lo largo de la guerra civil, para después tener una importancia nodal en el proceso de la consumación de la independencia en el año de 1821, cuando los comandantes Anastasio Bustamante y Luis Cortazar fueron proclamando y jurando el Plan de Iguala en algunas de sus poblaciones y finalmente en su capital el 24 de marzo. En una primera parte se hablará de la importancia que tuvo la región para los gobiernos virreinal e insurgente, que se empeñaron en mantenerla bajo su dominio, para después analizar el peso que llevaron sus comandantes y autoridades políticas en la coyuntura trigarante de 1821 . Fue en esta provincia donde comenzó la guerra, la madrugada del 16 de septiembre de 1810, y en ella también se dio el inicio del fin, cuando se adhirió en marzo de 1821 al movimiento iturbidista, volviéndose uno de sus principales bastiones.

\section{LA MANZANA DE LA DISCORDIA. EL BAJÍO DURANTE LA GUERRA INSURGENTE}

La intendencia de Guanajuato representó durante el último siglo de dominio español una de las regiones más prósperas y ricas, pues su desarrollo superó en mucho al resto de regiones del virreinato. También conocido como "el granero de la Nueva España", el Bajío contemplaba la intendencia de Guanajuato y el corregimiento de Querétaro, donde a partir de la segunda mitad del siglo XVIII se dio un gran auge económico basado en el aumento de las extracciones plateras, pero también en la consecuente demanda y crecimiento de una agricultura e industria que diera sustento a los diversos poblados que se dedicaron a la explotación mineral. 5

363; "Creación de subdelegaciones en la intendencia de Guanajuato, 1790-1810", Rafael DiegoFernández Sotelo, Graciela Bernal Ruiz y José Luis Alcauter Guzmán (coord.), Subdelegaciones novohispanas. La jurisdicción como territorio y competencia, Zamora, El Colegio de Michoacán / Universidad de Guanajuato / Universidad Autónoma de Zacatecas, 2019, pp. 71-104.

4 Véanse Joaquín E. Espinosa Aguirre, "Que diez hombres parezcan cientos. Un ensayo de militarización cuantitativa en la comandancia de Guanajuato (1813-1817)", en Estudios de Historia Moderna y Contemporánea de México, número 61, enero-junio 2021, pp. 3-35; "Todo importa menos que la puntual paga de las tropas. Juntas de arbitrios y penuria económica en Guanajuato durante el sexenio absolutista (1814-1820)", Boletín del Archivo General de la Nación, novena época, 5, mayo-agosto 2020, pp. 32-63; "Fin de la guerra, ¿fin de la militarización? Las fuerzas armadas en Guanajuato en la transición a la vida independiente (1816-1824)", en Graciela Bernal Ruiz y Mariana Terán Fuentes (coord.), Después de la guerra, el comienzo. Independencia, pacificación y reconstrucción en México, Madrid, Sílex Ultramar, 2021, p. 23-58.

5 A decir de Erick Wolf, "el Bajío y sus alrededores [...] no dependía por completo de la minería”, ya que su economía era el resultado de la combinación única entre la minería, la agricultura y la industria, tres características que no estuvieron presentes simultáneamente en 


\section{Mapa 1. Intendencias de Nueva España (siglo XVIII)}

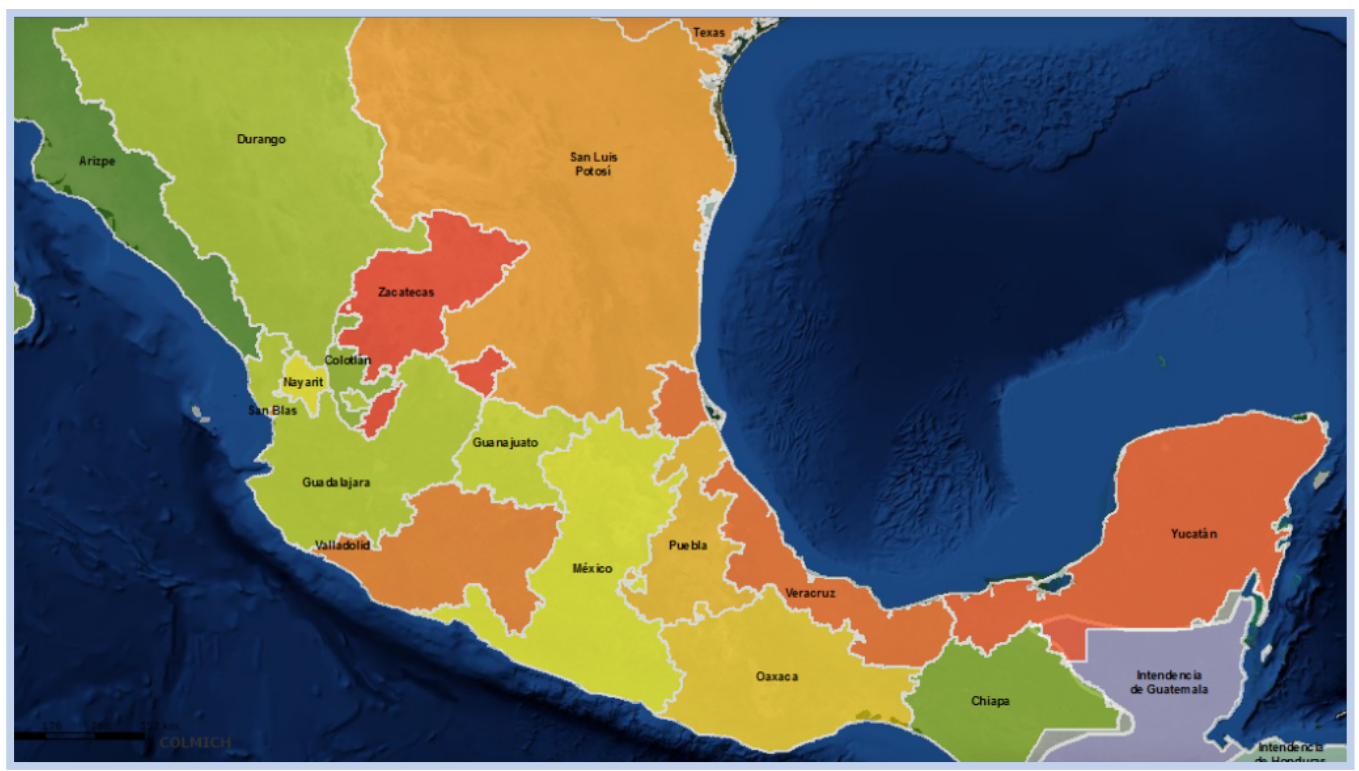

Fuente: Mapa “División político territorial de la América borbónica (siglo XVIII)", tomado de la página del Colegio de Michoacán a escala 1:9.421.686. Consultado el 19 de julio de 2018 en: http://colmichsig.colmich.edu.mx/DPTAB/Default.aspx.

De ahí la necesidad por proteger esta región, ya que ella significaba un espacio de la mayor importancia económica, que si bien vino a la baja desde el periodo de la consolidación de Vales Reales, no perdió su preponderancia en el contexto novohispano. Más aún cuando las tensiones monetarias, fomentadas por las repetidas crisis agrícolas de inicios de siglo, asi como los propios desencuentros entre sectores sociales, protagonizados sobre todo por criollos y peninsulares, detonaron con un movimiento que dirigido por una baja aristocracia criolla se fue impregnando de las demandas y requerimientos de los grupos más vulnerables y desposeídos: los indios y las castas. Con ello, la rebelión tomó tintes mucho más radicales y violentos, como demuestran algunas escenas vividas en la alhóndiga de Granaditas, en la capital guanajuatense, o en Valladolid y Nueva Galicia, donde se presentaron matanzas masivas de peninsulares. ${ }^{6}$

En consecuencia, la provincia guanajuatense pasó de ser un enclave de la producción gubernamental, a un espacio simbólico de la insurgencia, lo cual determinó a las autoridades en la búsqueda de su recuperación. Para tal efecto, a fines de 1810, el comandante Félix María Calleja marchó hacia la ciudad y logró controlarla una vez que sus tropas entraron "a sangre y fuego" en el poblado. ${ }^{7}$ José

otros sitios. Eric Wolf, "El Bajío en el siglo XVIII. Un análisis de integración cultural”, op. cit., pp. 68-75.

6 A este respecto, véanse los trabajos de Marco Antonio Landavazo, "De la razón moral a la razón de Estado: violencia y poder en la insurgencia mexicana", Historia Mexicana, LIV: 3, 2004, pp. 834-839; y "Para una historia social de la violencia insurgente: el odio al gachupín", Historia Mexicana, LIX: 1, 2009, pp. 195-200.

7 Juan E. Hernández y Dávalos (dir.), Colección de documentos para la historia de la guerra de independencia de México de 1808 a 1821, 6 vols., México, Instituto de Investigaciones Históricas; Universidad Nacional Autónoma de México, 2010, tomo IV, documento 162, p. 1: "Carta de Calleja 
Antonio Serrano ha señalado que los "castigos a la 'plebe' sirvieron para que los patricios y los vecinos principales regresaran al bando realista", pues a partir de ese momento, la oligarquía provincial se inclinaria definitivamente hacia la fidelidad al rey, no siempre por una convicción relacionada al modo de gobierno monárquico, pero sí basados en el rechazo a los horrores vividos en las primeras semanas de la guerra. ${ }^{8}$

En los meses posteriores, el brazo militar y politico intentó reponer "todas las cosas al ser y estado que tenían antes de que el fuego de la infame rebelión se introdujera", y para ello Calleja nombró nuevas autoridades. Al frente quedó, como intendente, Fernando Pérez Marañón, quien hasta entonces se había desempeñado como alférez real, en tanto que la insurgencia se reagrupaba alrededor de la Suprema Junta Nacional Americana, cuya sede se encontró en la villa de Zitácuaro, entre las provincias de Guanajuato y Valladolid. Desde ahí, la rebelión se redistribuyó, nombrando comandante de la demarcación del Norte a José María Liceaga, al tiempo que radicalizó su postura política al asumir la soberanía en sus manos. ${ }^{9}$

El gobierno virreinal, por su parte, presentó un cambio en su dirigencia a partir de 1813, recayendo el cargo de virrey justamente en el brigadier Calleja. Con él, se comenzó a desarrollar una reforma del sistema defensivo que consistió en la creación de comandancias militares que custodiaran de una manera más organizada y coordinada a las provincias. Además, se fundaron dos centros de mando en donde se posicionarian los Ejércitos del Sur y del Norte, correspondiendo a Guanajuato el segundo de esos cuerpos. Con esta media, se buscaba antes que nada atender la imperiosa necesidad económica, pues en el sur se pretendía asegurar el traslado de los tabacos de Orizaba y Córdoba y los convoyes venidos del puerto de Veracruz, en tanto que en el norte se quería proteger el traslado de la plata y el fomento de la agricultura y el comercio. ${ }^{10}$

Para tal tarea, el virrey destinó al coronel criollo Agustín de Iturbide, quien se había desempeñado hasta entonces en la labor de trasladar los cargamentos de plata de la capital de la provincia de Guanajuato hacia la ciudad de Querétaro así como combatir a las gavillas rebeldes que se desempeñaban en la región. ${ }^{11}$ En

al virrey sobre ejecuciones y estado de la insurrección”, México, noviembre 28 de 1810.

8 José Antonio Serrano Ortega, Jerarquía territorial y transición politica. Guanajuato 1790-1836, op. cit., p. 85.

9 Moisés Guzmán Pérez, La Suprema Junta Nacional Americana y la Independencia. Ejercer la soberanía, representar la nación, Morelia, Universidad Michoacana de San Nicolás de Hidalgo, Gobierno del Estado de Michoacán, Consejo Nacional para la Cultura y las Artes, 2011, pp. 163179 y 265. El gobierno político quedó en manos del intendente José Joaquín Pagola Olloqui, desde octubre de 1812 .

10 Joaquín E. Espinosa Aguirre, "La imperiosa ley de la necesidad. Guanajuato y la génesis de las comandancias militares novohispanas", Revista Tiempo y espacio, XXXVI: 67, enero-junio de 2017, pp. 176199.

11 Véase Joaquín E. Espinosa Aguirre, "De miliciano a comandante. La trayectoria miliciana de Agustín de Iturbide (1797-1813)", Tzintzun. Revista de Estudios Históricos, 69, enero-junio de 2019, pp. 67-97. Para este momento, Iturbide había logrado vencer al bandido Albino Garcia, a quien fusiló junto a su hermano en el mes de junio de 1812; al comandante Liceaga, a quien evacuó de la laguna de Yuriria en octubre y noviembre siguientes; así como derrocar a los hermanos Ramón y Rafael López Rayón en la batalla de Salvatierra, en abril de 1813, victoria que sirvió para catapultarlo hacia el nombramiento de comandante del Bajío. 
adelante, sería él quien se encargara de aplicar la estrategia contrainsurgente que planteó Calleja, basada en tres puntos fundamentales: el primero consistente en la recuperación económica, sobre todo con la protección de los rubros de agricultura, comercio y minería, tal como se dejó ver en su bando al tomar el mando del virreinato, con el que dio la pauta de sus objetivos:

[que se] mantenga libre la comunicación con la Nueva Galicia, San Luis Potosí y las Provincias Internas; proteja el envío de platas, ganado y semillas a esta capital; disperse las fuerzas de Rayón y demás cabecillas y dé impulso al tráfico interior que es el único medio de encontrar recursos independientes de la voluntad siempre mezquina de los particulares, para sostener la tropa y recoger caudales con que auxiliar esa Metrópoli. ${ }^{12}$

De ahí se desprende el segundo elemento: derrotar a los diversos grupos insurrectos de la región, para lo que Iturbide contaría con los elementos de la Tercera División del Ejército del Norte, que debian dar persecución a los enviados de la Junta Nacional así como a los bandidos que se propagaban por la región. A su vez, se buscaba que estuvieran despejados los caminos entre la capital del virreinato y Querétaro, así como los que llevaban hacia San Luis Potosí y Zacatecas, con el fin de avanzar en el cuidado de los recursos argentíferos que se encontraban en estas jurisdicciones y su comercio. ${ }^{13}$

Finalmente, para procurar el cuidado y la protección de los diversos poblados del Bajío, se debían organizar cuerpos de fieles realistas, que constaban de compañias urbanas creadas de acuerdo con el Reglamento político militar publicado en 1811 por Calleja, en ese entonces comandante del Ejército del Centro, y que en 1813 fue revalidado en su calidad de virrey. ${ }^{14}$ Estos cuerpos serian los encargados de contener a los diversos grupos de rebeldes y gavillas, principales amenazas de la región por estos años.

Durante el periodo en que Iturbide se encargó de la comandancia de Guanajuato y el Bajío, la economía tuvo un pequeño repunte, sobre todo a partir de la recuperación de minería y agricultura, apoyado en la relativa tranquilidad que se vivió gracias a la neutralización de los cabecillas rebeldes. Desde diciembre de 1813, en que José María Morelos fue vencido en las Lomas de Santa Maria por las fuerzas de Iturbide y Ciriaco de Llano, comandante general del Ejército del Norte, y luego en Puruarán en los primeros días de enero de $1814,{ }^{15}$ la insurgencia perdió presencia en la provincia de

12 "Al tomar el mando del virreinato", Calleja al Ministro de la Guerra, México, 15 de marzo de 1813, Boletin AGN, tomo I, número 1 (septiembre-octubre de 1930), pp. 85-86

13 "Instrucción para la División de la Provincia de Guanajuato", Félix María Calleja a Agustín de Iturbide, México, 27 de abril de 1813, en Agustín de Iturbide, Correspondencia y diario militar de don Agustín de Iturbide, 1810-1813, Secretaria de Gobernación, Imprenta de don Manuel León Sánchez / Talleres Gráficos de la Nación, México, 1923-1930, tomo I, pp. 37-38.

14 Félix María Calleja, "Reglamento político militar que deberán observar, bajo las penas que señala, los pueblos, haciendas y ranchos a quienes se comunique por las autoridades legitimas y respectivas, formado por el excelentísimo señor virrey", México, 5 de marzo de 1813, en Archivo General de la Nación (en adelante AGN), Impresos Oficiales vol. 58, exp. 64, ff. 154-160v.

15 La batalla de Santa Maria, a las afueras de la ciudad de Valladolid de Michoacán, fue el hecho de armas que marcó el declive militar del cura Morelos, en tanto que la ruina en Puruarán dio la estocada final, con la aprehensión del lugarteniente de Morelos, Mariano Matamoros, fusilado unos días después en la plaza de armas vallisoletana. 
Guanajuato, restando solamente pequeñas partidas al mando de los hermanos Francisco y Encarnación Ortiz, mejor conocidos como "los Pachones", Tomás Valtierra "Salmerón", Miguel Borja, Andrés Delgado, alias "el Giro", y el padre Torres, que fungió como comandante de la demarcación de 1815 a 1817.16 La insurgencia en Guanajuato no quedó eliminada, pero sí mayoritariamente contenida, relegada a las zonas fronterizas de la provincia y reducidas al posicionamiento defensivo.

Cuando se suscitó el cambio de régimen a causa de la abolición constitucional y el restablecimiento absolutista de "El Deseado" Fernando VII, la noticia fue recibida de manera diversa por las autoridades y sectores guanajuatenses. Mientras el comandante Iturbide decretó tres dias de fiesta a partir del 15 de octubre, en que hubo salvas de artillería y repique general de campanas, con la ceremonia del besamanos en su propia casa, rematándose con el fusilamiento de 50 rebeldes; ${ }^{17}$ otros sectores, sobre todo los rebeldes, manifestaron su escepticismo y desconfianza.

Ejemplo de ello fue el padre Torres, quien respondió a la invitación al indulto que le hizo el comandante español Pedro Celestino Negrete replicando que las miras de Bonaparte estaban puestas sobre América y buscaban "remachar los grillos a la España, valiéndose del instrumento del infeliz Fernando", quien según el cura habia sido liberado con sospechosa facilidad por el corso. Apelaba al decreto de Cortes sobre no reconocerse libre al rey "y por lo mismo no se le preste obediencia hasta que en el seno del Congreso preste juramento", concluyendo con una incómoda pregunta a Negrete, pero a su vez a todos los sostenedores de la contrainsurgencia novohispana: "¿Qué partido tomará la facción de gachupines de América? ¿El del monarca o el de las Cortes?”. ${ }^{18}$

Esta postura recuerda mucho a los argumentos que daría en 1820 el célebre Servando Teresa de Mier, cuando cuestionó a las mismas autoridades al referir el bando de Valencia de mayo de 1814, donde según Mier se habían declarado ilegítimos los gobiernos españoles durante la ausencia real, volviendo a "las Cortes, un puñado de facciosos, y la Constitución, un crimen de lesa majestad", a lo que las propias Cortes respondieron decretando que no se debía reconocer al rey. Mier cuestionaba a las autoridades de la siguiente manera:

¿Cuál de los dos decretos vale? Si el de Fernando, ustedes que reconocieron aquellos gobiernos y cortes y juraron la Constitución, son facciosos y criminales de lesa majestad: y leales los insurgentes que no reconocieron aquéllos ni juraros ésta aunque reconocian por rey a Fernando. Si vale el decreto de las Cortes, los insurgentes no reconociéndole más por rey, hacen lo que ustedes debieran haber ejecutado si no fuesen traidores y rebeldes a la nación representada en las Cortes

16 Moisés Guzmán Pérez, "Práctica bélica en la revolución novohispana: la guerrilla del padre José Antonio Torres, 1814-1818", Historia Caribe 15, 36 (enero-junio 2020), pp. 180-182; Eugenio Mejía Zavala, "La transición a un gobierno republicano. La Junta Subalterna de la insurgencia (1815-1820)", en José Antonio Serrano Ortega (coord.), El sexenio absolutista. Los últimos años insurgentes Nueva España (1814-1820), Zamora, El Colegio de Michoacán, 2014, pp. 358.

17 Agustín de Iturbide a Félix María Calleja, Irapuato, 30 de diciembre de 1814, en Agustín de Iturbide, Correspondencia y diario militar, op. cit., tomo II, pp. 318-323.

18 "Contestación del padre Torres a Negrete, refiriéndole la verdadera situación de España, e invitándole a que tome parte por la independencia”, Pénjamo, 13 de julio de1814, en Juan E. Hernández y Dávalos (dir.), Colección de documentos para la historia de la guerra de independencia de Mpexico de 1808 a 1821, op. cit., tomo VI, documento 259, pp. 1-3. 
en quien juraron reconocer la soberanía, y perjuros de Dios, ante quienes juraron con la Constitución no reconocer por rey a Fernando si no la juraba igualmente. Con que en todo caso, ustedes, y no los insurgentes, son los traidores y rebeldes. ${ }^{19}$

Lo cierto es que las autoridades no estaban preparadas para este nuevo cambio de rumbo respecto a la politica metropolitana, pues como se ha mostrado en algunos estudios recientes, la abolición de las instituciones gaditanas se dio de manera paulatina en algunos casos, mientras que en otros simplemente no se pudo verificar, y acabaron proyectándose una serie de medidas que respondian más a las aspiraciones liberales que a los postulados del Antiguo Régimen, todo bajo el amparo de que "se irá proveyendo". ${ }^{20}$

Mientras las autoridades buscaron "borrar del tiempo los años de 1810 a 1814" durante el sexenio absolutista, la situación armada en Guanajuato presentó ciertos cambios, comenzando con el pseudo proceso judicial que se llevó a cabo en contra de Agustín de Iturbide, acusado de realizar ciertos abusos y excesos sobre las poblaciones civiles, y que decantó en su destitución como comandante de la región. No obstante, si bien la provincia presentaba un gran avance en su pacificación cuando Iturbide dejó su cargo, una nueva amenaza estaba por llegar.

Consecuente también de la restitución fernandista, y de su posterior vuelco hacia el absolutismo, el otrora guerrillero navarro Xavier Mina habia cambiado su postura ante la autoridad regia, y en busca de acabar con su tiranía, se dirigió a Nueva España con intenciones de independizarla y fundar un gobierno republicano. Para ello, las autoridades encabezadas por Apodaca se prepararon militarmente, y Guanajuato volvió a ser un centro de atención. Fue el comandante Pascual de Liñán quien orquestó la defensa de la intendencia, la cual en unos pocos meses logró sofocar a la desavenida dirigencia insurgente, dividida entre el desconfiado padre Torres y el recién llegado Mina, encontrando éste su cadalso a mediados del mes de noviembre de 1817 en el cerro del Bellaco, al norte de la ciudad de Guanajuato, en tanto que el sistema de fuertes de la rebelión se lograba desmantelar. ${ }^{21}$

Tras la muerte de Mina, la estrategia contrainsurgente plantó una nueva cara, distribuyéndose territorialmente en tres departamentos para la defensa: mientras su nuevo comandante general, Antonio de Linares, se encargaba de la región central, habría dos comandancias regionales, una en el norte, a órdenes de

19 Servando Teresa de Mier, "Manifiesto apologético", en Fray Servando Teresa de Mier, Memorias, México, Conaculta, 2008, pp. 408-409.

20 Manuel Chust Calero y José Antonio Serrano Ortega, Tras la guerra, la tempestad. Reformismo borbónico, liberalismo doceañista y federalismo revolucionario en México (1780-1835), Madrid, Universidad de Alcalá / Marcial Pons, 2019, p. 138; José Antonio Serrano Ortega: "Las herencias ilustradas y gaditanas en tiempos del absolutismo. Nueva España (1814-1819)", en José Antonio Serrano Ortega (coord.): El Sexenio absolutista, los últimos años insurgentes: Nueva España (1814-1820), op. cit., pp. 191-227; Joaquín E. Espinosa Aguirre, “Todo importa menos que la puntual paga de las tropas. Juntas de arbitrios y penuria económica en Guanajuato durante el sexenio absolutista (1814-1820)", op. cit., pp. 32-63.

21 Gustavo Pérez Rodríguez, Xavier Mina, el insurgente español. Guerrillero por la libertad de España y México, México, Instituto de Investigaciones Históricas; Universidad Nacional Autónoma de México, 2018, pp. 367-384. 
Francisco de Orrantía, y otra al sur, bajo la jurisdicción de Anastasio Bustamante, quien había llegado desde Puebla para hacerle frente a la Expedición de Mina, y cuyas labores en adelante resultarian determinantes. ${ }^{22}$ En coordinación, los tres comandantes se encargaron de aislar a los dirigentes insurgentes, tanto de los pueblos que les brindaban su apoyo como entre ellos mismos, logrando debilitarlos y acabar prácticamente con ellos.

En enero de 1819, el comandante Linares pudo señalar la eficacia de esta medida al virrey, diciendo que "son conocidas las ventajas de las operaciones combinadas de todas las secciones". ${ }^{23}$ Empero, tras la guerra vendría la tempestad, pues otras noticias de la Península estaban por llegar, y la conquistada tranquilidad de la región se vería afectada de nueva cuenta.

\section{DESATAR EL NUDO SIN ROMPERLO. EL PACÍfICO TRIUNFO DE LA TRIGARANCIA}

Las noticias del triunfo que logró el movimiento constitucionalista liderado por Rafael del Riego y Antonio Quiroga movieron hasta sus cimientos al virreinato de Nueva España. Como había sucedido con las abdicaciones de Bayona, la promulgación de la carta gaditana y la restauración fernandista, ahora se volvía a dar un golpe de timón en la politica metropolitana, generándose un ambiente de incertidumbre que sería aprovechado por un nutrido grupo de militares, que como Riego y los suyos, decidieron tomar en sus manos el futuro de su gobierno y apoderarse del control.

El encargado de dar unidad a ese grupo fue el antiguo comandante Agustín de Iturbide, quien desde 1816 se encontraba en un retiro forzado. En el mes de noviembre de 1820 Iturbide había sido nombrado comandante del Sur y rumbo de Acapulco, y a partir de entonces comenzó a desplegar una enorme maquinaria política y militar que terminarian con la proclamación del Plan de independencia de la América Septentrional en Iguala, el 24 de febrero de 1821.

Como esto demostró, los hombres de armas en América y particularmente Nueva España habían cobrado consciencia de la rentabilidad que podría generarles el dejar de pedir y comenzar a exigir, pues el "ejemplo" dado allende el mar sería aplicado por Agustín de Iturbide y sus allegados. ${ }^{24}$ Ellos consideraban, como bien recupera Catherine Andrews, que "las autoridades peninsulares en lugar de agradecer los diez años de trabajo constante, pretendía arrebatarles la única prerrogativa de que gozaban”, que era el dominio de sus regiones de influencia. ${ }^{25}$

22 Catherine Andrews, Entre la espada y la constitución. El general Anastasio Bustamante, $1780-$ 1853, Universidad Autónoma de Tamaulipas, Ciudad Victoria, 2008, p. 43.

23 Antonio de Linares al virrey conde del Venadito, Celaya, 19 de enero de 1819, Gaceta del gobierno de México, martes 9 de febrero de 1819, en Hemeroteca Nacional de México (en adelante HNM), p. 131.

24 Rodrigo Moreno Gutiérrez, La trigarancia. Fuerzas armadas en la consumación de la independencia. Nueva España, 1820-1821, México, Instituto de Investigaciones Históricas; Universidad Nacional Autónoma de México, 2016, pp. 76 y 80.

25 Catherine Andrews, Entre la espada y la constitución. El general Anastasio Bustamante, 17801853, op. cit., p. 52. 
Por ello es que, incluso antes de la publicación del plan, el objetivo del comandante del Sur fue el de atraerse a algunos oficiales, criollos en su mayoría, que respaldaran sus aspiraciones y ambiciones por transformar la politica novohispana. De ese modo, según señala en su Manifiesto publicado en 1831, Manuel Gómez Pedraza le habría proporcionado a Iturbide algunas "esquelas" con información sobre elementos que podrian considerarse como posibles aliados: figuraban los nombres de Joaquín Parres, José Antonio Echávarri y Anastasio Bustamante, siendo el último el que resultaria la pieza clave para insurreccionar el Bajío guanajuatense. ${ }^{26}$

Es posible que el primer encuentro entre él e Iturbide se haya dado en agosto de 1812, cuando el Bustamante se dirigió a Querétaro al cuidado de los cargamentos de plata. 27 Por ello es que seguramente fue más sencillo contactarlo cuando, en enero de 1821, Iturbide envió comunicaciones reservadas, a través de oficiales del regimiento de Celaya que tenían su confianza, a ciertos personajes de la región de Nueva Galicia, Valladolid y el Bajío, entre los que figuran Luis Quintanar, Miguel Barragán y Luis Cortazar, así como Bustamante y Parres, tal como señaló Gómez Pedraza. ${ }^{28}$

Bustamante respondió el día 6 de febrero, desde la hacienda de Pantoja, en el sur de la intendencia de Guanajuato, señalándole a Iturbide que haría lo que estuviera de su parte y le permitieran sus circunstancias para complacerlo, aunque también se excusó por enfermedad para poderlo acompañar en sus "gloriosas marchas y fatigas". ${ }^{29}$ Este pretexto sería común entre los oficiales contactados, pues así evitaban comprometerse en caso de que sus comunicaciones cayeran en manos de las autoridades virreinales.

Esta respuesta confirmaría la versión que había llegado hasta Iturbide acerca de la postura que guardaba la provincia donde se había desarrollado como comandante años atrás, ya que según le confesó a su compadre Juan Gómez Navarrete, "me han asegurado que la provincia de Guanajuato delira por la independencia, y que [...] se habla con mucha libertad en favor de ella". ${ }^{30}$

No debe extrañar que la región del Bajío clamara por un cambio, pues si bien se había verificado un mediano avance en la recuperación de las actividades mineras, que para 1818 y 1819 se habian regenerado en la mina más importante de la provincia, La Valenciana, para alcanzar una producción de casi 175 mil

26 Manuel Gómez Pedraza, Manifiesto, que..., ciudadano de la República de Méjico, dedica a sus compatriotas; o sea una reseña de su vida pública, Nueva Orleáns, Imprenta de Benjamín Levy, 1831 , p. 9.

27 Agustín de Iturbide al virrey Félix María Calleja, 16 de agosto de 1813, en Agustín de Iturbide, Correspondencia y diario militar, op. cit., tomo I, pp. 179-180.

28 Rodrigo Moreno Gutiérrez, La trigarancia. Fuerzas armadas en la consumación de la independencia. Nueva España, 1820-1821, op. cit., pp. 152-153; “Oficio de don Celso de Iruela, Teniente del Regimiento de Celaya”, Celso de Iruela a Iturbide, Hacienda del Molino, 14 de marzo de 1821, en El Mejicano independiente, número 5, sábado 7 de abril de 1821, p. 53.

29 William S. Robertson, Iturbide de México, traducción, introducción y notas de Rafael Estrada Sámano, presentación de Jaime del Arenal Fenochio, México, Fondo de Cultura Económica, 2012, p. 109; Catherine Andrews, Entre la espada y la constitución. El general Anastasio Bustamante, 1780-1853, op. cit., p. 58.

30 Iturbide a Gómez Navarrete, [Teloloapan], 15 de diciembre de 1820, citado en Rodrigo Moreno Gutiérrez, La trigarancia. Fuerzas armadas en la consumación de la independencia. Nueva España, 1820-1821, op. cit., p. 157. 
pesos el primer año y 200 mil el segundo, ${ }^{31}$ lo cierto era que la economía de la Hacienda provincial no estaba ni cerca de ser saludable. En contraste con la minería, el déficit que existía en la tesorería militar en el periodo de julio de 1818 a julio de 1819 ascendía a 9,500 pesos mensuales, lo que se incrementó en el mes de agosto a 15 mil, y a 30 mil en diciembre. ${ }^{32}$ Por si fuera poco, las intensas lluvias del año de 1820 provocaron nuevas inundaciones en Celaya, Irapuato y otras poblaciones, lo que afectó todavía más la producción minera.

Y a pesar de que Bustamante refería a inicios de 1820 que su jurisdicción se encontraba en total calma, por "la tranquilidad y grandes bienes de la paz establecida"; detrás de esa apariencia estaban estos males, quizás mayores a los que habian logrado erradicarse. Por su parte, en mayo, el comandante general Linares también describía una provincia que se encontraban "sin perturbarse ni ligeramente [en] el orden y la tranquilidad pública", 33 pero la realidad lo alcanzó el $1^{\circ}$ de diciembre, cuando las tropas dejaron de recibiría su paga, en tanto que el déficit había llegado hasta rondar los 40 mil pesos, lo que a su vez generaba escasez de armas y uniformes, atrayendo la deserción en masa. ${ }^{34}$

Estas carencias las habian adelantado los vecinos principales de Guanajuato desde 1816, cuando señalaron al virrey que estaban:

agotados los arbitrios del vecindario y destruida su importante minería que era el patrimonio, el fondo radical de su subsistencia política y natural; ya no encuentra medios para conservar a las tropas en los diversos puntos que necesita. Los generosos mineros, este cuerpo interesantísimo de toda la Monarquía Española, después de haber sufrido radicalmente como se ha manifestado en diversas manifestaciones, todo el peso de la guerra y todo el trastorno de la revolución, han hecho incalculables sacrificios a favor de la causa pública y del Rey [...] Pero agobiados ya con tan crecidas contribuciones, casi aniquilados sus fondos metálicos, y reducidos ya estos hombres ricos a lo muy preciso para vivir y sostener sus familias, han llegado por fin al grado de imposibilidad en la continuación de sus servicios. ${ }^{35}$

31 María Eugenia Romero Sotelo, Mineria y guerra. La economía de Nueva España, 1810-1821, Facultad de Economía; Universidad Nacional Autónoma de México / El Colegio de México, México, 1997, pp. 214-215. Cuadro 8 "Producción y gastos de la mina La Valenciana, de 1788 a 1810 y de 1811 a $1825 "$.

32 Catherine Andrews, Entre la espada y la constitución. El general Anastasio Bustamante, 1780 1853, op. cit., p. 48. "Cuadro que compara los ingresos y egresos de la tesorería militar de Guanajuato (1818-1819)".

33 Antonio de Linares al virrey conde del Venadito, Salamanca, 2 de mayo de 1820, en Gaceta del gobierno de México, martes 30 de mayo de 1820, en HNM, pp. 518-520. Mismas noticias tuvo desde esa fecha a septiembre por parte de las demarcaciones del Jaral con Manuel José Martínez; la capital Guanajuato de Pedro Antonio Yandiola; de Froilán Bocinos en San Miguel de Allende; de Luis Quintanar en Pénjamo; y de Salamanca por parte de Anastasio Bustamante.

34 Brian R. Hamnett, “Anastasio Bustamante y la guerra de independencia, 1810-1821", Historia Mexicana, núm. 112, v. XXVIII, abril-junio 1979, p. 532; Catherine Andrews, Entre la espada y la constitución. El general Anastasio Bustamante, 1780-1853, op. cit., pp. 45 y $49-50$.

35 Fernando Pérez Marañón, Mariano de Otero, Pedro Otero, José Antonio Carillo y otros a Juan Ruiz de Apodaca, Guanajuato, 7 de diciembre de 1816, en AGN, Operaciones de Guerra, vol. 640 . 
Era tan apremiante la situación de la provincia de Guanajuato, que el Semanario Politico y Literario dedicó su número 36 a unas "Reflexiones sobre los productos de las minas de Guanajuato el año de 1820". En él, se señalaba que desde inicios de ese año se había logrado la pacificación de la provincia y que estaban liberados los caminos, pero en cuanto a la minería se denunciaba un estancamiento impropio de las riquezas de la provincia. La culpa, decían, se debía a que "la historia de Guanajuato en estos últimos años es la de un pueblo arruinado por las contribuciones", ello como consecuencia de que "el comandante militar que recorría toda la provincia fijase más la atención en exprimirle hasta las últimas gotas de su sustancia con un escandaloso monopolio, con contribuciones y empréstitos, que en obrar la pacificación del territorio que se le había confiado". Eran, pues, más los males que padecía la ciudad por la mala administración de los recursos que por la propia guerra: "acabose la insurrección y el mal todavía progresa", concluían las reflexiones. ${ }^{36}$

A pesar de toda esa situación, Bustamante informó a la superioridad en sus reportes de los días 3, 10, 17 e incluso 24 de febrero de 1821, que "no ha habido novedad". Linares, por su parte, habia dicho al virrey que "sigue tranquila toda esta provincia sin que ocurra accidente alguno que perturbe su actual feliz estado". 37 No obstante, como recoge Brian Hamnett, circulaba el rumor de un posible movimiento conspirativo que daría un nuevo "grito" desde el Bajío, a lo que el virrey no dio crédito. ${ }^{38}$ Pero, como vimos, en ese momento la maquinaria trigarante ya había sido echada a andar.

Por lo anterior se puede confirmar que para febrero de 1821 el ambiente se encontraba dispuesto para el pronunciamiento. A decir de Rodrigo Moreno, no sería descabellado pensar que para fines del mes anterior ya estaban cuando menos establecidos los ejes del proyecto de independencia, y de esa forma se dio a conocer en Iguala, donde se proponía una alternativa pacífica a la ansiada emancipación de la vieja España, bajo los postulados fundamentales de la independencia, la religión católica, apostólica y romana como la oficial del reino, y la unión entre americanos y españoles. ${ }^{39}$

Las noticias sobre "la conspiración y [el] anticonstitucional proyecto del

36 "Reflexiones sobre los productos de las minas de Guanajuato el año de 1820", en Semanario Político y Literario, número 36, miércoles 21 de marzo de 1821, en HNM, p. 75. Se señalaba que el sector minero había sido abandonado de tal manera que en 1820 se producía apenas la quinta parte con respecto al año de 1810, y por lo que se observa en la mina La Valenciana, se podría confirmar, ya que la disminución en su producción sufrió una caída de los 1,385,611 pesos en 1809 a 80,183 en 1820. María Eugenia Romero Sotelo, Minería y guerra. La economía de Nueva España, 1810-1821, op. cit., pp. 214-215. Cuadro 8 "Producción y gastos de la mina La Valenciana, de 1788 a 1810 y de 1811 a $1825 "$.

37 Brian R. Hamnett, "Anastasio Bustamante y la guerra de independencia, 1810-1821", op. cit., p. 533, apoyado en Bustamante a Linares, Valle de Santiago, 2, 10, 17 y 24 de febrero de 1821, en AGN, Operaciones de Guerra vol. 475, ff. 314, 328, 349 y 378; Antonio de Linares al virrey conde del Venadito, Celaya, 16 de enero de 1821, en Gaceta del gobierno de México, martes 30 de enero de 1821, en HNM, p. 101. Seguía tal cual 12 de febrero.

38 Brian R. Hamnett, “Anastasio Bustamante y la guerra de independencia, 1810-1821", op. cit., p. 533. Se desconoce si este rumor guardaba alguna relación con la revolución de Iguala.

39 Agustín de Iturbide, "Proclama que acompaña al Plan de Independencia publicado en Iguala”, 24 de febrero de 1821, en Agustín de Iturbide, Escritos diversos, México, Conaculta, 2014, pp. 34-38. 
coronel don Agustín de Iturbide" llegaron a oídos de las autoridades de la provincia de Guanajuato por medio de una circular enviada por el virrey Apodaca el 28 de febrero, en la que las conminaba a "seguir cumpliendo a toda costa con el juramento que hemos hecho de [...] ser fieles al rey, y obedecer las leyes".40 A ello, Linares respondió asegurando que "yo como las autoridades de la provincia de mi mando, esteremos siempre unidos a las disposiciones de Vuestra Excelencia en que reconoceremos el legítimo gobierno emanado de la Monarquía española a que pertenecemos", toda vez que circulaba la información a los comandantes subalternos de su demarcación. ${ }^{41}$

No es claro lo que sucedió entre la respuesta de Bustamante a Iturbide del 6 de febrero, la proclamación del Plan de Iguala el 24 siguiente, y la jura de dicho plan el $1^{\circ}$ de marzo, pero lo seguro es que para la segunda quincena de ese mismo mes comenzaron a removerse las poblaciones del Bajío, instigadas la mayoria de las ocasiones por oficiales y jefes que movilizaron a sus tropas en favor de la trigarancia. Desconcierta la "dulce sorpresa" con que presuntamente Bustamante recibió la noticia del levantamiento, pues en una comunicación posterior preguntó retóricamente a Iturbide "¿cuál pues sería mi satisfacción al recibir el pliego de Vuestra Señoría de 24 del último febrero, en que me comunicaba su plan, anunciándome que iba a proclamarlo el primero del próximo pasado marzo?".42 Quizás Bustamante quería evitar descubrir su compromiso inicial, o posiblemente solo se tratara de una expresión para comunicar su júbilo por la publicación del plan.

El caso es que para ese momento, Anastasio Bustamante se habia atraído al comandante de Salvatierra, teniente coronel Luis Cortazar, quien "se hallaba tan decidido como yo por la causa de la Nación". Este comandante había proclamado la independencia entre "las demostraciones más plausibles de entusiasmo" en el poblado de Amoles el 16 de marzo; en Salvatierra el 17, donde la guarnición se declaró a favor "a pesar de su comandante", el teniente coronel Reguera, y en Valle de Santiago el 18, con presencia de los destacamentos de esa localidad y de Pénjamo. Dos días después, por orden de Bustamante, Cortazar avanzó a Salamanca para tratar de adherirse a Antonio de Linares, pero éste logró retirarse hacia Celaya y dar aviso al virrey Ruiz de Apodaca sobre los pronunciados; era la única alternativa que tenía, ya que sólo contaba con 200 hombres. ${ }^{43}$

Cortazar alcanzó en Celaya a Linares, quien se negó ante su ofrecimiento de tener el mando trigarante de la provincia, razón por la cual fue mantenido preso hasta el arribo de Bustamante, quien respetaba mucho a Linares, por lo que tras conferenciar con él, le dio un pasaporte y una escolta para trasladarse hacia Querétaro. En la población encontraron resistencia del escuadrón del Príncipe y

40 "Circular del Venadito", México, 28 de febrero de 1821, en Vicente Rocafuerte, Bosquejo ligerísimo de la Revolución del Mégico, desde el grito de Iguala hasta la proclamación imperial de Iturbide, por un Verdadero Americano, México, Conaculta, 2008, p. 173.

41 Antonio de Linares al virrey conde del Venadito, Guanajuato, 6 de marzo de 1821, en Gaceta del gobierno de México, martes 13 de marzo de 1821, HNM, p. 245.

42 "Provincia de Guanajuato", Bustamante a Iturbide, Villa de León, 3 de abril de 1821, en El Mejicano independiente, número 7, sábado 21 de abril de 1821, p. 67.

43 "Provincia de Guanajuato", Bustamante a Iturbide, Villa de León, 3 de abril de 1821, en El Mejicano independiente, número 7, sábado 21 de abril de 1821, p. 68; Catherine Andrews, Entre la espada y la constitución. El general Anastasio Bustamante, 1780-1853, op. cit., p. 60. 
el piquete Ligero de Querétaro, que "se mantenían en sus cuarteles con intención de defenderse", pero Bustamante logró persuadirlos de unirse a su causa, en tanto que a los jefes y oficiales "que no han adoptado nuestro partido" les dio pasaporte y auxilio para salir a sus destinos respectivos. ${ }^{44}$

De ese modo, quedaron también Celaya y Salamanca en sus manos, lo que les permitió avanzar hacia la hacienda de Burras, lugar desde donde el cura Hidalgo intimó al intendente Juan Antonio Riaño en septiembre de 1810, y desde donde ahora en 1821 Bustamante anunció su entrada a la ciudad de Santa Fe de Guanajuato. El pliego de la intimación fue enviado al ayuntamiento por medio del capitán de infantería de Celaya, Francisco Quintanilla, para ser leído a primera hora del 24 de marzo por los capitulares y el intendente:

Debiendo pasar en la mañana de hoy a esa capital la valiente división que tengo el honor de presidir, con el preciso objeto de proclamar nuestra feliz suspirada independencia; lo anuncio a Vuestras Señorias para su debido conocimiento, esperando [que] de su entusiasmo patriótico interpongan toda su autoridad y respeto a fin de que ese heroico pueblo guarde el mejor orden, moderación y unión [...] a lo que sin disputa contribuirá mucho la pacífica voz de los ministros del altar, uniformando la opinión y exhortando al vecindario a la unión con todas las clases, y principalmente con nuestros hermanos de Europa, cuyas vidas y propiedades deberán ser para nosotros inviolables. ${ }^{45}$

El tono de su solicitud era sumamente diplomático, a la vez que vehemente, ya que no solicitaba la recepción de sus tropas, sino que lo avisaba. No obstante, la advertencia sobre la moderación de su marcha pretendía ser un pacto con las élites de la ciudad, compuestas por peninsulares y criollos, al tiempo de buscar poner de su lado al brazo clerical, para que no tuvieran empacho en aceptar su llegada de buena gana. Apenas terminó de darse lectura al aviso, las autoridades acordaron que una comisión, compuesta por los regidores José María García de León y Francisco Echeverria, así como el diputado de minería Tomás Alamán, se dirigieran hacia Burras para invitar a Bustamante a conferenciar directamente con el ayuntamiento.

Una vez llegado el comandante, Pérez Marañón solicitó que le diera la certidumbre sobre que la capital no tendría más afectaciones, tras lo cual podría dejar el mando de la provincia para después retirarse de ella. Bustamante respondió que su tropa estaba dispuesta para "derramar la última gota de su sangre" en favor de la felicidad de la América, pero también mostraba una crecida convicción, ya que aseguró que nada ni "nadie podría impedirle proclamar aquí la independencia [...] en vista de la respetable fuerza que traía consigo, y que se hallaba ya ocupando la plaza principal de esta ciudad";46 no se trataba de negociar la capitulación, sino de los términos sobre los cuales se llevaría a cabo.

44 "Provincia de Guanajuato", Bustamante a Iturbide, Villa de León, 3 de abril de 1821, en El Mejicano independiente, número 7, sábado 21 de abril de 1821, pp. 69-70.

45 Lucio Marmolejo, Efemérides Guanajuatenses o datos para formar la historia de la ciudad de Guanajuato, 4 volúmenes, Guanajuato, Imprenta del Colegio de Artes y Oficios, 1883-1884, tomo III, pp. 157-158.

46 Lucio Marmolejo, Efemérides Guanajuatenses o datos para formar la historia de la ciudad de Guanajuato, op. cit., tomo III, pp. 158-159. 
No existía otra alternativa, pues en ese momento el intendente se había quedado solo en la capital debido a que el 23 de marzo el comandante Pedro Yandiola se habia retirado precipitadamente con rumbo hacia la villa de León, en espera de obtener apoyo por parte de José de la Cruz. ${ }^{47}$ Además, para entonces, tanto los miembros del ayuntamiento como las fuerzas que se mantenían en la capital ya se habían dejado seducir por el canto de las sirenas, y estaban inclinados por la independencia. Se trataba de un mero trámite declarar una postura ante el comandante trigarante, pues su voluntad ya se había adherido extraoficialmente.

Así pues, tras la entrevista de las autoridades, se verificó el ingreso de las tropas independentistas "entre vivas y aclamaciones", acompañadas de descargas de artillería y un repique general de campanas. Entre las fuerzas dirigidas por Bustamante y Cortazar estaban algunos ex insurgentes (varios indultados para 1820), entre los que se encontraba el Pachón Encarnación Ortiz, Miguel Borja y otros más, sumados nuevamente al bando de la independencia. Algunos días después, Bustamante creó una casa de moneda, aunque no sin la oposición de los miembros del ayuntamiento.

En esta victoria, el mayor peso lo habian tenido los cuerpos armados de las compañías del Ligero de Querétaro, de San Carlos y la Sierra, a quienes se habian unido Joaquín Parres, sargento mayor de Dragones fieles del Potosí, el teniente Mariano Guevara del Escuadrón de Sierra Gorda y el alférez Luis Flores con el mando de una partida del Regimiento de San Luis. ${ }^{48}$ El brazo militar se había dejado sentir en toda su dimensión política; como arma para ejercer presión, pero sin llegar a empuñar las armas violentamente.

Estas halagüeñas noticias invitaron a que Iturbide se dirigiera hacia el Bajío en el mes de abril, pues la presión que tenía en el sur del virreinato parecía estar extinguiendo la flama de su insurrección. De mucho sirvió que para ese momento hubiera recibido reportes sobre estar controladas por fuerzas trigarantes las poblaciones de Pátzcuaro, Tacámbaro, Turicato y Apatzingán, en Michoacán, y Silao, León, Irapuato y otros puntos de Guanajuato, por lo que el Primer Jefe pudo atravesar por la Tierra Caliente hacia Zitácuaro, Maravatío y finalmente Salvatierra, donde se reunió con los jefes Bustamante, Cortazar y Parres el día $18 ; 49$ desde ahí podría preparar los siguientes pasos a dar por parte del movimiento.

A su paso por la región, Iturbide fundó un cuerpo armado que se encargaría de resguardar el Bajío y sus alrededores, las "Compañias Patrióticas de Caballería de Guanajuato, auxiliares del Ejército de las Tres Garantias", pues todavia estaban pendientes de rendir los poblados de San Miguel el Grande y Dolores, al

47 Graciela Bernal Ruiz, "Guanajuato en el proceso de la independencia mexicana, 1820-1823”, en Jaime Olveda, La consumación de la independencia en las provincias novohispanas, México E1 Colegio de Jalisco, 2021 (en prensa). Es curioso que Yandiola no apoyara al movimiento, pues hasta entonces había guardado una relación algo cercana con Iturbide. Agradezco a la autora por facilitarme el manuscrito.

48 "Provincia de Guanajuato", Bustamante a Iturbide, Villa de León, 3 de abril de 1821, en El Mejicano independiente, número 7, sábado 21 de abril de 1821, pp. 69-70. Graciela Bernal Ruiz, "Guanajuato en el proceso de la independencia mexicana, 1820-1823", op. cit.

49 “Huetamo 4 de abril”, en El Mejicano independiente, número 5, sábado 7 de abril de 1821 , p. 54. 
norte de la intendencia. Estas compañias, que quedaron al mando del teniente coronel Gaspar López, tendrían principalmente el objetivo de:

conservar la tranquilidad y seguridad de los campos, auxiliar los pueblos cuando se tenga alguna conmoción popular, hostilizar y recolectar toda fuerza enemiga que entre en la provincia, [...] aprehender y desarmar todo desertor y sospechoso que no lleve el pasaporte correspondiente, [así como] estar pronta para cuando convenga que obre unida al Ejército, en cuyo caso está socorrida por la Tesorería Nacional el tiempo que se empleé.

La importancia del Bajío, tan conocida por Iturbide, seguía vigente, y por ello lo dotó de una división de estos cuerpos intermitentes de milicia para el cuidado de sus caminos y de los caudales que podrian obtenerse de él. En cuanto al pago de las fuerzas, señaló que se debería solicitar por los comandantes de los 10 distritos a su ayuntamiento constitucional o gobierno de cabecera, "para que esta haga un reparto muy moderado a las haciendas de él para cubrir estos gastos". ${ }^{50}$

Ante la desconfianza de algunos peninsulares, fomentada por las autoridades virreinales para generar división en el movimiento independentista, sobre que serian ejecutadas una especie de "vísperas sicilianas" apenas obtenido el triunfo definitivo, Iturbide dio a conocer una proclama desde la villa de León el $1^{\circ}$ de mayo. En ella, el Primer Jefe confesaba que

He llegado a entender que algunos espíritus, enemigos de la paz y de la humanidad, a vista de los rápidos progresos que hace notoriamente la causa de la independencia, sin que hasta ahora se haya derramado por mi parte una sola gota de sangre, intentan alarmaros con especies subversivas que excitan vuestra desconfianza.

Pero los tranquilizaba al comprometer las "caras prendas de mi corazón", que eran un padre europeo y una esposa e hijos vulnerables que podrian hablar de su compromiso por la causa de la independencia, si es que su "palabra de honor, la más sagrada" no bastaba. ${ }^{51}$

El siguiente logro que obtuvo en esos días el líder del movimiento trigarante fue el de pactar una reunión el 8 de mayo con el comandante de Nueva Galicia, el brigadier José de la Cruz, quien si bien no se sumó al movimiento, al menos fue aparentemente "neutralizado" y declinó cualquier intento por hostilizar la provincia de Guanajuato. De este modo, se pudo evitar la efusión innecesaria de sangre, además conseguirse sumar al teniente coronel Juan José Pastor con

\footnotetext{
50 "Instrucciones para los comandantes de distrito y de fuerza patriótica armada para la seguridad del campo y auxilio del ejército", Agustín de Iturbide, Silao, 23 de abril de 1821, en Archivo Histórico Municipal de León (en adelante AHML), caja 1821-3, expediente 7; "Distribución de Distritos con expresión con expresión [sic] de los comandantes de cada uno, en el Bajío de la provincia de Guanajuato", Agustín de Iturbide, Silao, 23 de abril de 1821, en AHML, caja 1821-3, expediente 8 .

51 Carlos María de Bustamante, Cuadro histórico de la revolución mexicana de 1810, segunda edición corregida y muy aumentada, 8 volúmenes, México, Instituto Nacional de Estudios Históricos de la Revolución Mexicana, 1985, tomo V, pp. 143-144.
} 
algunos oficiales y 200 dragones de Querétaro. ${ }^{52}$

A continuación, a mediados de ese mismo mes, la vanguardia del Ejército de las Tres Garantías se dirigiría hacia la provincia michoacana. Para su rendición, las fuerzas se organizaron alrededor de la capital: mientras Barragán y Parres se colocaron en el sur y oriente de la ciudad de Valladolid, Iturbide y Bustamante franquearon la parte poniente. Esto ayudó a que, tras varios días de negociaciones, se lograra pactar una capitulación, para entrar triunfales el día 22 a la ciudad natal del Primer Jefe. ${ }^{53}$ Este triunfo les ganó "un crecido número de armas, y municiones, habiéndose pasado al Ejército [trigarante] una porción de tropas de esta guarnición, y queda por nuestra toda la provincia”, según informó Bustamante, así como un mayor crédito al movimiento gracias a haberse apoderado de su segunda capital provincial. 54

En junio siguiente, tocaría el turno al corregimiento de Querétaro, por lo que correspondió a Bustamante y Quintanar posicionarse en San Juan del Río, al sureste de dicha ciudad, y evitar que la ayuda enviada desde la ciudad de México por conducto de Manuel de la Concha pudiera llegar y dar auxilio al sitio impuesto sobre la ciudad queretana. Los buenos movimientos de los trigarantes obligaron a ese oficial virreinal a realizar una "violenta retirada" desde Río Frío hacia la capital. Posteriormente, Bustamante, Cortazar y Juan José Codallos se reunieron en San Luis de la Paz, al norte, para cerrar el paso al apoyo que podría venir desde la intendencia de San Luis Potosi. ${ }^{55}$

Por entonces, Bustamante aprovechó para proclamar la independencia en el pueblo de Zimapán el 19 de julio, de donde tomó la cantidad de 10,000 pesos de la hacienda real, con lo que se desahogó la precariedad monetaria y se pudo reforzar la presencia trigarante en Huichapan e Ixmiquilpan. Ya unos dias antes, a finales de junio, Iturbide había solicitado un préstamo de la provincia de Guanajuato por 20,000 pesos, distribuidos por el intendente entre las poblaciones de la capital, León, Silao e Irapuato; al que se sumaría posteriormente otra solicitud por 25,000.56

Una vez con el control de Querétaro, el siguiente peldaño sería acercarse al sur del virreinato y a la ciudad de México. Por ello, Bustamante se dirigió hacia el centro del país, en tanto que se encargaba a Pedro Otero el mando de Guanajuato

52 "Provincia de Guanajuato", Bustamante a Iturbide, Villa de León, 11 de abril de 1821 , en El Mejicano independiente, número 8, sábado 28 de abril de 1821, p. 81.

53 Carlos Juárez Nieto, Guerra, Politica y Administración en Valladolid de Michoacán: La formación profesional y la gestión del intendente Manuel Merino, 1776-1821, Morelia, Secretaría de Cultura de Michoacán, 2012, pp. 650-652.

54 Anastasio Bustamante al comandante de León, Francisco Castillo, Valladolid, 22 de mayo de 1821, en AHML, caja 1821-2, expediente 11.

55 Antonio de Castro a Nicolás Bravo, Texcoco, 4 de agosto de 1821, en La correspondencia de Agustín de Iturbide después de la proclamación del Plan de Iguala, 2 volúmenes, advertencia e introducción de Vito Alessio Robles, México, Secretaría de la Defensa Nacional, 1945, tomo II, p. 153; Catherine Andrews, Entre la espada y la constitución. El general Anastasio Bustamante, 17801853, op. cit., p. 62; Rodrigo Moreno Gutiérrez, La trigarancia. Fuerzas armadas en la consumación de la independencia. Nueva España, 1820-1821, op. cit., pp. 208-209.

56 Juan Arago al comandante militar de la Villa de León, Guanajuato, 26 de junio de 1821, en Archivo Histórico Municipal de León (en adelante AHML), Caja 1821-2, expediente 9; Graciela Bernal Ruiz, "Guanajuato en el proceso de la independencia mexicana, 1820-1823", op. cit. 
y el Bajío. ${ }^{57}$ No se podía bajar la guardia, pues si bien el movimiento había dado grandes avances, gracias a las victorias obtenidas, el triunfo no estaba asegurado. Prueba de ello es que. desde el mes de junio, los oficiales trigarantes se mantenían en alerta permanente debido a que José de la Cruz se había declarado "abiertamente enemigo" de la causa independiente, por lo que comisionó al antiguo comandante de Guanajuato Yandiola para llevar información a la ciudad de México y traer las respuestas del virrey. ${ }^{58}$

Todo empeoró cuando se supo que el gobierno del virrey Apodaca habían dado "por nulas las capitulaciones hechas en el reino, y [ha] mandado que los capitulados se reúnan a México", con lo que se temió que muchos que se habían rendido pudieran volver a insurreccionarse contra la causa trigarante. ${ }^{99}$ Ahí fue donde cobraron más importancia las instituciones politicas, principalmente con el compromiso mostrado hacia la causa trigarante por parte de los miembros del ayuntamiento constitucional de la ciudad de Guanajuato, restituido por la nueva vigencia de la Constitución de la Monarquía. Como ha señalado José Antonio Serrano, "la derrota del gobierno colonial en 1821 trajo consigo un vacío políticoadministrativo que fue ocupado por los ayuntamientos, las diputaciones provinciales y los caudillos militares", fortalecidos durante la guerra y la inducción del sistema liberal gaditano. 60

Hay que recordar que Guanajuato no contó con una Diputación Provincial cuando las Cortes gobernaron en 1812, y sólo se permitió que enviara diputados para integrarse a la de San Luis Potosí. Tampoco contaron con una en 1820, ya que según la orden de las Cortes ordinarias de Madrid del 24 de enero de 1821, debía integrarse a la de Michoacán. ${ }^{61}$ Pero, para el año de 1821, Iturbide secundó la tardía decisión de las Cortes de Madrid de crear Diputaciones en nueve provincias, lo que refrendó la Junta Provisional Gubernativa el 8 de noviembre. De ese modo, el órgano político guanajuatense no quedaría establecido sino hasta el 25 de febrero de 1822, ya en el periodo del Imperio. ${ }^{62}$ Por ello fue que el ayuntamiento de la capital provincial tendría tanto peso.

Sin embargo, quien más responsabilidad cargó en este proceso fue sin duda la corporación militar, ${ }^{63}$ quien finalmente el 8 de julio de 1821

57 Pedro Otero al teniente coronel Francisco Castillo, Guanajuato, 30 de junio de 1821, en AHML, caja 1821-2, expediente 29.

58 Agustín de Iturbide al teniente coronel Francisco Castillo, San Felipe Casas Viejas, 25 de junio de 1821, a las 10 de la mañana, en AHML, caja 1821-2, expediente 18; Narciso Pinto al comandante militar de la Villa de León, Lagos, 27 de junio de 1821, en AHML, caja 1821-2, expediente 24 .

59 Pedro Otero al comandante militar de León, Guanajuato, 20 de agosto de 1821, en AHML, caja 1821-2, expediente 39.

60 José Antonio Serrano Ortega, "El ascenso de un caudillo en Guanajuato; Luis de Cortázar 1827-1832”, en Historia Mexicana, XLIII (1993), p. 51.

61 "Noticias nacionales", Semanario Politico y Literario, número 41, miércoles 25 de abril de 1821, HNM, pp. 213-214.

62 José Antonio Serrano Ortega, "Estudio Introductorio. Sin diputación propia: los grupos politicos guanajuatenses en las Diputaciones de San Luis Potosí (1812-1814 y 1820-1821) y de Guanajuato (1822-1824)", en Diputación provincial de Guanajuato. Actas de sesiones, Instituto de Investigaciones Dr. José María Luis Mora / El Colegio de Michoacán, México, 2016, pp. 26-30.

63 De esto he hablado en otro lugar. Véase Joaquín E. Espinosa Aguirre, "Fin de la guerra, ¿fin 
organizó la jura solemne de la independencia en la capital de la provincia. Así lo refirió a Agustín de Iturbide el comandante de Guanajuato Pedro Otero, señalándole que se había realizado la ceremonia, como se les había ordenado, "con presencia y apoyo de los capitulares, el Ayuntamiento constitucional, la Diputación de Minería, los ministros de las Rentas públicas, los curas y prelados religiosos y varios vecinos distinguidos". Entre ¡vivas! a la religión, la independencia y la unión, acompañadas de música militar, Guanajuato vio llegado así el día de "su felicidad y libertad". 64

\section{A MODO DE CONCLUSIÓN}

E1 26 de julio de 1821 las fuerzas libertadoras ya estaban a las afueras de la Ciudad de México. Ahí esperaron mientras Iturbide se dirigía a la villa de Córdoba a entrevistarse con el recién llegado Juan de O' Donojú. Todo parecía controlado, hasta que el 19 de agosto las tropas de Bustamante y Felipe Codallos se enfrascaron en una ligera escaramuza en el pueblo de Azcapotzalco con la fuerza de Francisco Buceli y Manuel de la Concha, provocada por una imprudencia de los trigarantes. El encuentro tuvo lugar en el atrio de la iglesia del poblado y lo más destacable fue que en el intento por apoderarse de un cañón atascado en el lodo murió el Pachón Ortiz, además de la muerte de un centenar de hombres por cada bando. ${ }^{65}$ Ese fue el último enfrentamiento armado de la guerra, previo a la marcha victoriosa. El 27 de septiembre, el Primer Jefe Iturbide ingresó triunfal a la capital del otrora virreinato, comenzando la vida independiente del Imperio mexicano.

De ese modo, la independencia que se consiguió en 1821 en poco se parecía a la comenzada en 1810. Triunfó un proyecto con mecanismos profundamente distintos, y que sólo se enlazaba con el de los insurgentes en el fundamental elemento de la emancipación politica. Sin embargo, el movimiento trigarante no estuvo, como ninguno lo está, con la victoria asegurada desde el inicio, sino que pasó graves dificultades en los primeros dias de sus marchas, logrando el impulso determinante gracias a los triunfos obtenidos por los comandantes del Bají, que consiguieron apoderarse del control de su capital apenas un mes después de proclamado el plan de independencia.

La clave se debió más que nada a que las fuerzas armadas lograron ser encausadas rápidamente hacia la trigarancia, pues como se vio, los comandantes Bustamante y Cortazar actuaron de manera rápida, y muy probablemente premeditada, evitando desórdenes y caos entre las poblaciones. Asimismo, debe distinguirse que, muy opuesto a lo sucedido una década atrás, la capital de la

de la militarización? Las fuerzas armadas en Guanajuato en la transición a la vida independiente (1816-1824)", op. cit.

64 Pedro Otero al Primer Jefe del Ejército Imperial de las Tres Garantías, Guanajuato, 9 de julio de 1821, en La correspondencia de Agustín de Iturbide después de la proclamación del Plan de Iguala, op. cit., tomo II, pp. 111-112, 2 vol.; Juan Arago al comandante militar de León, Guanajuato, 25 de junio de 1821, en AHML, caja 1821-2, expediente 22.

65 Un relato de la batalla en Carlos María de Bustamante, Cuadro histórico de la revolución mexicana de 1810, op. cit., tomo V, pp. 235-237; Anastasio Bustamante al teniente coronel Pedro Otero, Azcapotzalco, 15 de septiembre de 1821, en AHML, caja 1821-2, expediente 42. En ella, Bustamante avisaba que "nuestra entrada en la capital del Imperio está ya muy próxima". 
provincia se rindió ante el nuevo "grito", apoyada en los cuerpos armados pero también respaldado por las élites y las instituciones de gobierno político. Esto se debió en mucho al comportamiento diplomático que procuró manifestar el coronel Bustamante, pues como refirieron los capitulares el 2 de abril, previo a la salida del contingente armado,

el sr. coronel D. Anastasio Bustamante [...] observó en su conducta personal y trato con las autoridades que gobiernan la mayor política y moderación [...] Conservó la mayor unión y fraternidad [con los vecinos particulares del pueblo], especialmente con los Europeos, cuyas vidas, honor, quietud y propiedad mantuvo ileso con particular cuidado, no menos que las de todos los habitantes de esta población, a quienes tampoco se advirtió que ofendieron en lo más mínimo los soldados del expresado sr. Bustamante; y si por contrario se les observó el mayor concebimiento en su trato social, sin que hasta ahora haya llegado a saber dicha ilustre Corporación que se excedieron embriagándose, armando quimeras o insultado a alguno, ni con título de alojamiento, bagajes ni otros auxiliares. 66

Un enorme cambio que redituó en grandes beneficios para la trigarancia, pues se atrajo la opinión de prácticamente toda la capital provincial, y con ello se obtuvo un notable avance respecto al control de toda la intendencia. Un ejemplo sumamente simbólico de esto resultó ser la ceremonia de retiro de las cabezas de los primeros insurgentes de las esquinas de la alhóndiga de Granaditas, donde se encontraban desde una década atrás, para después darles sepultura religiosa. Bien señala Hamnett que "la caída de las ciudades del Bajío, en marzo y abril de 1821, fue una hazaña de Bustamante", quien fungiría desde septiembre como segundo de Domingo Estanislao Luaces, comandante del Ejército del Centro, y posteriormente como miembro de la Junta Provisional Gubernativa, por lo que figuró como uno de los firmantes del Acta de independencia del Imperio mexicano, sancionada el 28 de septiembre. 67

Sin embargo, la patria independiente heredó problemáticas que con la simple firma de un acta dificilmente podrian ser superadas, pues una vez que las aspiraciones políticas y los diversos proyectos de nación quisieron ponerse en práctica, se encontraron con el dominio abrumador que existía por parte de los cuerpos militares. Esos militares que habían fungido como catalizador de la independencia, que ahora buscarian ser premiados y recompensados como lo fueron los liberales españoles de 1820.

Guanajuato es una muestra de ello, así como de otras problemáticas, protagonizadas por las carencias monetarias que habian generado los largos años de guerra. La vorágine insurgente afectó estructuralmente a la economía de la provincia, por lo que fue necesario emprender una contrainsurgencia por demás agresiva, que exigió a su vez la creación desmedida de cuerpos milicianos para

66 Sala Capitular, Guanajuato, 2 de abril de 1821, Archivo Histórico de la Universidad de Guanajuato (en adelante AHUG), Ramo de Guerra, caja 7, doc. 288.

67 Brian R. Hamnett, "Anastasio Bustamante y la guerra de independencia, 1810-1821", op. cit., p. 535; "Estado general de los ejércitos del imperio mejicano", Melchor Álvarez, Cuartel General en San Joaquín, 10 de septiembre de 1821, en Diario Politico Militar Mexicano, número 10, lunes 10 de septiembre de 1821, pp. 41-43; Catherine Andrews, Entre la espada y la constitución. El general Anastasio Bustamante, 1780-1853, op. cit., p. 64. 
contener al enemigo. Pero esta estrategia, fomentada por Calleja e Iturbide, a la larga generaría grandes males, pues acabaria por desecar sus arcas y afectar a las poblaciones. Esa rica y próspera región declinó económicamente poco a poco, hasta quedar relegada, en tanto que su control fue demandado por los mismos jefes militares.

Fue en esa coyuntura que la alternativa trigarante se recibió con tal entusiasmo, ya que consideraban necesario un golpe de timón en la política. Poco a poco, los poblados se manifestaron a favor del movimiento, hasta llegarse a jurar la independencia, pero inmediatamente después vino la nueva demanda inacabable de recursos para mantener en pie a los cuerpos libertarios. Por ello es que la penuria continuaria una vez instalado el Imperio mexicano, el que resultó ser tan efimero que no pudo, ni intentó, resolver esos problemas, y pasados unos meses, el emperador, antes celebrado y aplaudido, cayó en desgracia por sus malas decisiones políticas, ganándose un nuevo pronunciamiento militar que lo derrocaría. Ahora, como no dejaría de serlo a lo largo de las siguientes décadas, las decisiones politicas corrian a cargo de los militares. 


\section{REFERENCIAS}

\section{Archivos y acervos}

AGN

Archivo General de la Nación

AHUG

Archivo Histórico de la Universidad de Guanajuato

AHML Archivo Histórico Municipal de León

HNM

\section{Bibliografia}

Andrews, Catherine, Entre la espada y la constitución. El general Anastasio Bustamante, 1780-1853, Universidad Autónoma de Tamaulipas, Ciudad Victoria, 2008.

Bernal Ruiz, Graciela, "Creación de subdelegaciones en la intendencia de Guanajuato, 1790-1810”, Rafael Diego-Fernández Sotelo, Graciela Bernal Ruiz y José Luis Alcauter Guzmán (coord.), Subdelegaciones novohispanas. La jurisdicción como territorio y competencia, Zamora, E1 Colegio de Michoacán / Universidad de Guanajuato / Universidad Autónoma de Zacatecas, 2019, pp. 71-104.

Bernal Ruiz, Graciela, "El papel de los subdelegados en la contrainsurgencia. Guanajuato, 1810-1812”, Rafael Diego-Fernández Sotelo, María del Pilar Gutiérrez Lorenzo y Luis Alberto Arrioja Diaz Viruell (coord.), De reinos y subdelegaciones: nuevos escenarios para un nuevo orden en la América borbónica, Zamora, El Colegio de Michoacán / Universidad de Guadalajara / El Colegio Mexiquense, 2014, pp. 347-363.

Bernal Ruiz, Graciela, "Las ciudades de San Luis Potosí y Guanajuato en defensa de su preeminencia, 1786-1821", en Rubrica Contemporánea, vol. VIII, n. 15, 2019, pp. 5-24.

Bernal, Graciela, "Guanajuato en el proceso de la independencia mexicana, 18201823", en Jaime Olveda, La consumación de la independencia en las provincias novohispanas, México El Colegio de Jalisco, 2021 (en prensa).

Boletín del Archivo General de la Nación, tomo I, número 1, septiembre-octubre de 1930.

Brading, David A., Haciendas y ranchos del Bajio. León 1700-1860, traducción de Elia Villanueva Moreno, México, Grijalbo, 1988.

Bustamante, Carlos María de, Cuadro histórico de la revolución mexicana de 1810, segunda edición corregida y muy aumentada, 8 volúmenes, México, Instituto Nacional de Estudios Históricos de la Revolución Mexicana, 1985, tomo V.

Chust Calero, Manuel, y José Antonio Serrano Ortega, Tras la guerra, la tempestad. Reformismo borbónico, liberalismo doceañista y federalismo revolucionario en México (1780-1835), Madrid, Universidad de Alcalá / Marcial Pons, 2019.

Espinosa Aguirre, Joaquín E., "De miliciano a comandante. La trayectoria miliciana de Agustín de Iturbide (1797-1813)", Tzintzun. Revista de Estudios Históricos, 69, enero-junio de 2019, pp. 67-99. 
Espinosa Aguirre, Joaquín E., "Fin de la guerra, ¿fin de la militarización? Las fuerzas armadas en Guanajuato en la transición a la vida independiente (1816-1824)", en Graciela Bernal Ruiz y Mariana Terán Fuentes (coord.), Después de la guerra, el comienzo. Independencia, pacificación y reconstrucción en México, Madrid, Sílex Ultramar, 2021, p. 23-58.

Espinosa Aguirre, Joaquín E., "La imperiosa ley de la necesidad. Guanajuato y la génesis de las comandancias militares novohispanas", Revista Tiempo y espacio, XXXVI: 67, enero-junio de 2017, pp. 176-199.

Espinosa Aguirre, Joaquín E., "Que diez hombres parezcan cientos. Un ensayo de militarización cuantitativa en la comandancia de Guanajuato (1813-1817)", en Estudios de Historia Moderna y Contemporánea de México, número 61, enero-junio 2021, pp. 3-35.

Espinosa Aguirre, Joaquín E., “Todo importa menos que la puntual paga de las tropas. Juntas de arbitrios y penuria económica en Guanajuato durante el sexenio absolutista (1814-1820)", Boletín del Archivo General de la Nación, novena época, 5, mayo-agosto 2020, pp. 32-63.

Mejía Zavala, Eugenio, "La transición a un gobierno republicano. La Junta Subalterna de la insurgencia (1815-1820)", en José Antonio Serrano Ortega (coord.), El sexenio absolutista. Los últimos años insurgentes Nueva España (1814-1820), Zamora, El Colegio de Michoacán, 2014, pp. 331-374.

Gómez Pedraza, Manuel, Manifiesto, que..., ciudadano de la República de Méjico, dedica a sus compatriotas; o sea una reseña de su vida pública, Nueva Orleáns, Imprenta de Benjamín Levy, 1831.

Guzmán Pérez, Moisés, "Práctica bélica en la revolución novohispana: la guerrilla del padre José Antonio Torres, 1814-1818", Historia Caribe, XV: 36, enerojunio 2020, pp. 169-204.

Guzmán Pérez, Moisés, La Suprema Junta Nacional Americana y la Independencia. Ejercer la soberanía, representar la nación, Morelia, Universidad Michoacana de San Nicolás de Hidalgo, Gobierno del Estado de Michoacán, Consejo Nacional para la Cultura y las Artes, 2011.

Hamnett, Brian R., "Anastasio Bustamante y la guerra de independencia, 18101821 ”, Historia Mexicana, núm. 112, v. XXVIII, abril-junio 1979, pp. 515545.

Hamnett, Brian R., "Royalist Counter-insurgency and the Continuity of Rebellion: Guanajuato and Michoacán, 1813-1820", Hispanic American Historical Review, LXII: 1, febrero 1982, pp. 19-48.

Hamnett, Brian R., Raices de la insurgencia en México. Historia regional 17501824, traducción de Agustín Bárcena, México, Fondo de Cultura Económica, 1990.

Hernández y Dávalos, Juan E. (dir.), Colección de documentos para la historia de la guerra de independencia de México de 1808 a 1821, 6 vols., México, Instituto de Investigaciones Históricas; Universidad Nacional Autónoma de México, 2010 (disco compacto).

Iturbide, Agustín de, Correspondencia y diario militar de don Agustín de Iturbide, 1810-1813, Secretaría de Gobernación, Imprenta de don Manuel León 
Sánchez / Talleres Gráficos de la Nación, México, 1923-1930, tomo I y II.

Iturbide, Agustín de, Escritos diversos, México, Conaculta, 2014.

Juárez Nieto, Carlos, Guerra, Politica y Administración en Valladolid de Michoacán: La formación profesional y la gestión del intendente Manuel Merino, 17761821, Morelia, Secretaría de Cultura de Michoacán, 2012.

La correspondencia de Agustín de Iturbide después de la proclamación del Plan de Iguala, 2 volúmenes, advertencia e introducción de Vito Alessio Robles, México, Secretaría de la Defensa Nacional, 1945, tomo II.

Landavazo, Marco Antonio, "De la razón moral a la razón de Estado: violencia y poder en la insurgencia mexicana", Historia Mexicana, LIV: 3, 2004, pp. 833865.

Landavazo, Marco Antonio, "Para una historia social de la violencia insurgente: el odio al gachupín”, Historia Mexicana, LIX: 1, 2009, pp. 195-225.

Mier, Fray Servando Teresa de, Memorias, México, Conaculta, 2008.

Marmolejo, Lucio, Efemérides Guanajuatenses o datos para formar la historia de la ciudad de Guanajuato, 4 volúmenes, Guanajuato, Imprenta del Colegio de Artes y Oficios, 1883-1884, tomo III.

Moreno Gutiérrez, Rodrigo, La trigarancia. Fuerzas armadas en la consumación de la independencia. Nueva España, 1820-1821, México, Instituto de Investigaciones Históricas; Universidad Nacional Autónoma de México, 2016.

Pérez Rodríguez, Gustavo, Xavier Mina, el insurgente español. Guerrillero por la libertad de España y México, México, Instituto de Investigaciones Históricas; Universidad Nacional Autónoma de México, 2018.

Robertson, William S., Iturbide de México, traducción, introducción y notas de Rafael Estrada Sámano, presentación de Jaime del Arenal Fenochio, México, Fondo de Cultura Económica, 2012.

Rocafuerte, Vicente, Bosquejo ligerísimo de la Revolución del Mégico, desde el grito de Iguala hasta la proclamación imperial de Iturbide, por un Verdadero Americano, México, Conaculta, 2008.

Romero Sotelo, Maria Eugenia, Minería y guerra. La economía de Nueva España, 1810-1821, Facultad de Economía; Universidad Nacional Autónoma de México / El Colegio de México, México, 1997.

Serrano Ortega, José Antonio, "Dolores después del grito. Estrategias militares insurgentes y realistas en el norte de Guanajuato, 1810-1821", Tzintzun. Revista de Estudios Históricos, 61, enero-junio 2015, pp. 11-48.

Serrano Ortega, José Antonio, "El ascenso de un caudillo en Guanajuato; Luis de Cortázar 1827-1832”, en Historia Mexicana, XLIII (1993), pp. 49-80.

Serrano Ortega, José Antonio, "Estudio Introductorio. Sin diputación propia: los grupos políticos guanajuatenses en las Diputaciones de San Luis Potosí (1812-1814 y 1820-1821) y de Guanajuato (1822-1824)", en Diputación provincial de Guanajuato. Actas de sesiones, Instituto de Investigaciones Dr. José Maria Luis Mora / El Colegio de Michoacán, México, 2016, pp. 9-44.

Serrano Ortega, José Antonio, "La jerarquía subvertida: ciudades y villas en la 
intendencia de Guanajuato, 1787-1820", Marta Terán y José Antonio Serrano Ortega (edit.), Las guerras de independencia en la América española, México, El Colegio de Michoacán / Universidad Michoacana de San Nicolás de Hidalgo / Conaculta-INAH, 2002, pp. 403-422.

Serrano Ortega, José Antonio, Jerarquía territorial y transición politica. Guanajuato 1790-1836, Zamora, El Colegio de Michoacán / Instituto de Investigaciones Dr. José María Luis Mora, 2001.

Serrano Ortega, José Antonio: "Las herencias ilustradas y gaditanas en tiempos del absolutismo. Nueva España (1814-1819)", en José Antonio Serrano Ortega (coord.): El sexenio absolutista, los últimos años insurgentes: Nueva España (1814-1820), Zamora, El Colegio de Michoacán, 2014.

Wolf, Eric, "El Bajío en el siglo XVIII. Un análisis de integración cultural", David Barkin (comp.), Los beneficiarios del desarrollo regional, México, SEP Setentas, 1972, pp. 63-95.

Enviado el: 01/05/2021

Aceptado el: $7 / 05 / 2021$ 